\title{
Study of new energy-based noninvasive therapies for nonalcoholic fatty liver disease
}

\author{
Miachon MD* and Chavantes MC \\ Department of Medicine, University Nove de Julho, Brazil
}

\section{Introduction}

The incidence and prevalence of nonalcoholic fatty liver disease (NAFLD) and nonalcoholic hepatic steatosis (NAH) remain unknown. It is estimated that 20 to $40 \%$ of the Western population is affected by NAFLD. NAFLD is the most common form of chronic liver disease in the world, with an estimated prevalence of approximately $30 \%$ in the US. Most cases occur in people aged between 40 and 60 years, but NAFLD is becoming increasingly prevalent in the pediatric population [1]. Although initially it was considered a disease that predominantly affects the female sex, it is currently understood that both sexes are affected equally. It is believed that the prevalence in Hispanics is higher than in whites, while on the other hand, African Americans are less susceptible to the progressive form of the disease and the Asian and Pacific regions are less affected [2]. It is expected to become the main indication for liver transplantation in the future, replacing hepatitis $\mathrm{C}$.

As the prevalence of obesity and metabolic syndrome has increased on a global scale, there has also been an increase in nonalcoholic fatty liver disease (NAFLD). Its prevalence is significantly higher in diabetics (up to 63\%). In morbidly obese patients undergoing bariatric surgery and a liver biopsy, NAFLD was diagnosed in up to $93 \%$ of cases $[3,4]$

NAFLD is now a truly sneaky and silent epidemic. More than onethird of the adult Brazilian population has steatosis, which may be associated with other liver diseases (such as viral hepatitis or alcoholic liver disease), or associated with secondary factors (such as drugs, chemical agents), or with NAFLD, its main etiology.

It is known that NAFLD may progress to more severe forms such as nonalcoholic steatohepatitis (NASH), liver cirrhosis, or hepatocellular carcinoma. Furthermore, NAFLD is a warning sign for the future development of type 2 diabetes mellitus and cardiovascular diseases. An estimated $9 \%$ to $20 \%$ of patients with NAH evolve to cirrhosis, and up to one-third of these patients die from complications arising from liver failure or the need for liver transplantation [5,6]. In England, in the years 2015-2017, 774 deaths were reported as a result of NAFLD in people under 75 years of age $[7,8]$. Therefore, the current nonrecognition of the importance of this disease by the medical profession represents not only clinical ignorance, but above all, a lack of interest in their patients [8]

The incidence and prevalence of NAHS are difficult to assess due to the need for a biopsy to make the diagnosis. Data suggest that approximately $3 \%$ of individuals from developed countries have EHNA [6].

The term nonalcoholic steatohepatitis (EHNA) was used for the first time to describe a group of patients who developed liver failure after jejunoileal bypass surgery for obesity [9]. Nonalcoholic fatty liver disease is defined as a clinical-histopathological entity that includes a spectrum of conditions histologically characterized by macrovesicular hepatic steatosis in people who do not consume alcohol in amounts generally considered harmful to the liver [10].

Risk factors associated with nonalcoholic fatty liver disease (NAFLD) include medications, surgical procedures, or total parenteral nutrition, and these are considered by some to be secondary causes. Primary NAFLD is associated with metabolic syndrome or insulin resistance.

The pathophysiology of primary NAFLD is not yet fully understood, but the most accepted hypothesis is related to insulin resistance as the main mechanism, causing excess triglyceride accumulation in the liver and subsequent development of hepatic steatosis. When steatosis is present, some have proposed that a second attack or an additional oxidative lesion would be necessary to manifest the necro-inflammatory component observed in steatohepatitis. Antioxidant deficiencies; hepatic iron; fat-derived hormones including leptin, adiponectin and resistin; and intestinal bacteria were implicated as probable oxidative stressors. Therefore, nonalcoholic hepatic steatosis (EHNA) is a subset of NAFLD [11].

NAFLD can be classified into 5 forms of clinicopathological readyof-sight [12]:

- macrovesicular or mixed steatosis predominantly macro/ microvesicular without evidence of inflammation or fibrosis (mild).

- macrovesicular or mixed steatosis predominantly macro/ microvesicular with evidence of hepatocytes ballooning degeneration, mild, mixed, acute and chronic diffuse lobular inflammation, and perisinusoidal collagen deposition.

- fibrosis associated with EHNA: A wound healing response in damaged regions of the chronic inflammatory disease are encapsulated by extracellular matrix or scar tissue. In its early stages, fibrosis is considered reversible to some extent, but in the late stages, it is considered irreversible. In EHNA, fibrosis is classified in stages 0 to 4 .

- cirrhosis associated with HLH: this is the histological definition of the last stage of progressive hepatic fibrosis, characterized by distortion of the hepatic architecture and the formation of

*Correspondence to: Mateus Domingues Miachon, Department of Medicine, University Nove de Julho, Brazil, Tel: +55 (11) 3385-9241; E-mail: mateusmiachon@hotmail.com

Received: February 02, 2021; Accepted: February 18, 2021; Published: February 25, 2021 
regenerative nodules. Traditionally, it is considered an irreversible condition.

- End-stage liver disease associated with NAH: the stage that patients with cirrhosis develop clinical complications. Most complications are sequelae and manifestations of advanced fibrosis, such as portal hypertension and decreased synthetic liver function. They include ascites, portosystemic encephalopathy, varicose vein hemorrhage, hepatocellular carcinoma, and hepatorenal and hepatopulmonary syndromes.

\section{The pathological classification has 4 types:}

- Type 1: Simple steatosis, considered nonprogressive.

- Type 2: Steatosis associated with lobular inflammation (probably benign, not considered as EHNA).

- Type 3: Steatosis, lobular inflammation, and ballooning degeneration. It is EHNA without fibrosis (it may progress to cirrhosis and liver failure).

- Type 4: Steatosis, ballooning degeneration and fibrosis or Mallory bodies. It is EHNA with fibrosis (it may progress to cirrhosis and liver failure).

Regarding the treatment of NAFLD, so far there is no proven and conclusive therapy, demonstrating the importance of studies of potential therapeutic agents in this area. Since dietary and lifestyle modifications often fail or cannot be implemented efficiently, there is clearly a need for pharmacological agents for this condition, designed and studied with the aim of improving liver histology and liver function. Several agents with different mechanisms of action have been investigated, reflecting the different pathways considered important in the pathogenesis of NAFLD. The main lines of study involve drugs that improve insulin resistance and decrease oxidative stress [8].

\section{Photobiomodulation}

The word laser is composed of the first letters of the English expression Light Amplification by Stimulated Emission of Radiation, which means "amplification of light by stimulated emission of radiation". Lasers are used in medicine to provide the body with a better response, such as for cutting and vaporizing tumors. The laser is a symbol of technological advances, as it is on the list of the greatest inventions of the twentieth century. According to chavantes [13], the laser can be classified according to its power into 2 major groups: high power lasers (or surgical) and lasers that employ a low power, such as therapeutic low power light (LBP) and photodynamic therapy (PDT).

More recently, lasers have proven to be an excellent therapeutic tool, possessing biostimulatory capacity, as well as being part of modern therapies such as photobiomodulation therapy (TFBM). This is also known as simply laser therapy, which uses a laser or a low irradiance LED (LBI) (CHAVANTES, 2006).

LED stands for Light Emitting Diode. They are energy-based devices with laser-like effects. They promote light irradiation over larger areas for a shorter period of time. They have been developed in recent decades, are becoming cheaper, and produce similar effective responses to lasers during photobiomodulation therapy. In a pilot study of ARAUJO, the device was applied to patients with NAFLD, obtaining very promising results [14].

TFBM is being applied in several medical specialties with great success [15]. Due to the physical characteristics of the laser, it is possible to use it coupled to optical fiber instruments to reach areas of difficult access, enabling several complex surgeries, such as neurological and cardiovascular surgeries, endoscopic resections in the airways and digestive tract, and in gynecological and urological outpatient procedures [13]. The use of laser therapy in the postoperative period in patients undergoing major surgeries, such as cardio-thoracic surgeries, neurosurgeries, bariatric and other abdominal surgeries, have resulted in effective responses, reducing morbidities and apparently without adverse effects [15].

The FMT can be used to contain inflammation, with consequent reduction of edema, modulating the immunological process, minimizing painful symptomatology and cellular/tissue and organic biomodulation. Laser or LED therapy is an alternative for treating inflammatory responses, neoangiogenesis, pain and need for tissue regeneration [13].

A modified form of the use of low-power lasers is intravascular (arterial) applications. Known by its acronym ILIB, the English term Intravascular Light Irradiation of Blood (ILIB stands for Blood Intravascular Irradiation with Light). The Russians began to employ the technique of ILIB during the former Soviet Union-the Perestroika and Glasnost-however, due to the economic difficulties and situation in the Soviet bloc, it was not possible to import from the western medicines (antibiotics, oncology, etc.) and medical equipment. They began to seek new alternatives for the treatment of a number of intrahospital patients. Thus, several iron curtain countries have begun to successfully employ new forms of treatment in the various Soviet dialysis and ICUs services [16]. It can be applied directly to blood vessels or subcutaneously, according to chavantes [13] and KAZEMI [17], respectively, called Transvascular Sublingual Photo-Irradiation of Blood (Intravascular Irradiation with LED).

\section{Magnetotherapy}

Approximately 3,500 years ago, in the Iron Age, the concept of magnetism emerged in ancient Egypt, China and India. The first applications in inflammatory diseases and painful illnesses were reported in the years 131 to $201 \mathrm{BC}$. For centuries the magnetotherapy has been provided in the form of natural magnets, with a wide variety of properties, such as preventing or slowing down the process of cell aging and maintaining health. Studies on the properties of magnets continued in the 16th century with Aureolus Philippus Paracelsus (1493-1541), who used magnets to cure many inflammatory processes. At the end of the 18th century, Faraday paved the way for a new scientific conception of the association of electric currents and magnetism, studying the effects of electromagnetic fields.

Among the various types of treatments in the health area using magnetotherapy, there are low frequency pulsed electromagnetic fields (CEMP-BF). This is a noninvasive, safe and easy-to-manage method for the treatment of various pathologies characterized mainly by pain, inflammation and regeneration, causing biological effects on organisms, systems and organs. There are many doubts regarding the best dosage to be used with pulsed electromagnetic fields (CEMP), and their mechanisms of action are not fully understood. Its main actions are the diversion of particles with moving electrical charges, the production of induced currents through the piezoelectric effect on bones and collagen tissue, and increased solubility of substances. At the cellular level, it has a normalizing effect of membrane potential and stimulates cellular metabolism; in tissue, it is a powerful metabolic stimulator of cells, tissues and organs. 
Regarding the origin of magnetotherapy, its therapeutic use began at the end of the 19th century with D'Ansorval, but studies advanced a lot when, in 1957, Fukuda and Yasuda [18] described the piezoelectric phenomenon in bone tissue. From these studies, it was noticed that the effects obtained in bone regeneration with CEMP are not only due to the mechanical energy applied to $\mathrm{Ca}+$ ions $^{++}$, which makes these ions vibrate at their maximum frequency until they reach resonance (energy that will be transformed into electricity by the piezoelectric phenomenon), but also to the responses of osteocytes that release autocrines and paracrines, modulating factors of cellular activity.

The effects of magnetotherapy on bone tissue were evaluated in clinical studies such as that by Martinez, Capellas and Tinoco [19], which evaluated the treatment of fractures of long bones with 28 sessions of magnetotherapy, lasting 30 minutes per day, at a frequency of $50 \mathrm{~Hz}$ and intensity of $8 \mathrm{mT}$. The results showed consolidation of the fractures. The clinical study by McLeod et al. evaluated the effects of magnetotherapy on osteopenia, performing 60-minute CEMP sessions at frequencies of 15,75 and $150 \mathrm{~Hz}$. The results indicated that the frequency of $15 \mathrm{~Hz}$ was the most effective to increase bone mass [20].

CEMP can help treat osteoarthritis by decreasing pain. McCarthy's study CJ evaluated applications of $0.1-64 \mathrm{~Hz}, 30$ minutes per day for 3 weeks [21]. It was concluded that CEMP suppressed collagen matrix degradation enzymes, with preservation of cartilage morphology and a delay in the development of osteoarthritic lesions.

Nindl studied the anti-inflammatory effect of CEMP, using a frequency of $50 \mathrm{~Hz}$, and found it caused apoptosis of T lymphocytes [22]. On the other hand, CEMP does not perform well in inflammation caused by bacteria.

\section{Overall goal}

To conduct a comparative study of LED therapy and magnetotherapy in the treatment of nonalcoholic fatty liver disease.

\section{Case series and methods}

A randomized clinical trial, placebo-controlled, is proposed. The study will be carried out at the Medical Specialty Outpatient Clinic of Universidade Nove de Julho - UNINOVE at Rua Vergueiro, 235/249, Liberdade, São Paulo/SP.

In all patients, peripheral venous blood (Vacutainer ${ }^{\circledR}$ ) samples will be collected twice, once at the beginning and again after 20 weeks. The following will be measured:

- Serum proteins (only before the study period, as part of the inclusion/exclusion criteria)

- Fasting glucose and glycated hemoglobin (only before the study period, as part of the inclusion/exclusion criteria)

- Urea and creatinine (only before the study period, as part of the inclusion/exclusion criteria)

- Serology for hepatitis (only before the study period, as part of the inclusion/exclusion criteria)

- Alanine aminotransferase (ALT)

- Aspartate aminotransferase (AST)

- Alkaline phosphatase (FAL)

- Total bilirubin (BT), indirect (BI) and direct (BD)

- Gamma-glutamyl transpeptidase (GGT)
- Prothrombin uptime (TAP)

- Total Cholesterol (CT)

- Cholesterol HDL

- Cholesterol LDL

- Triglycerides

The sample will be divided into 3 groups at random, as described below:

Group 1: Patients with Placebo.

Group 2: Patients treated with transvascular LED therapy + magnetotherapy.

Group 3: Patients treated with magnetotherapy.

\section{LED therapy transvascular}

The LED (Linealux Laser Therapy ${ }^{\mathrm{ma}}$ ) will be applied by means of an applicator (A Teflon plate) with 3 LED outputs or 3 points of light application (one at the top and 2 at the bottom). A Continuous Wave LED Diode will be applied in red, $\lambda \pm 660 \mathrm{~nm}$, via the transvascular sublingual, at 3 points on the sublingual vessels, in the following dosimetry:

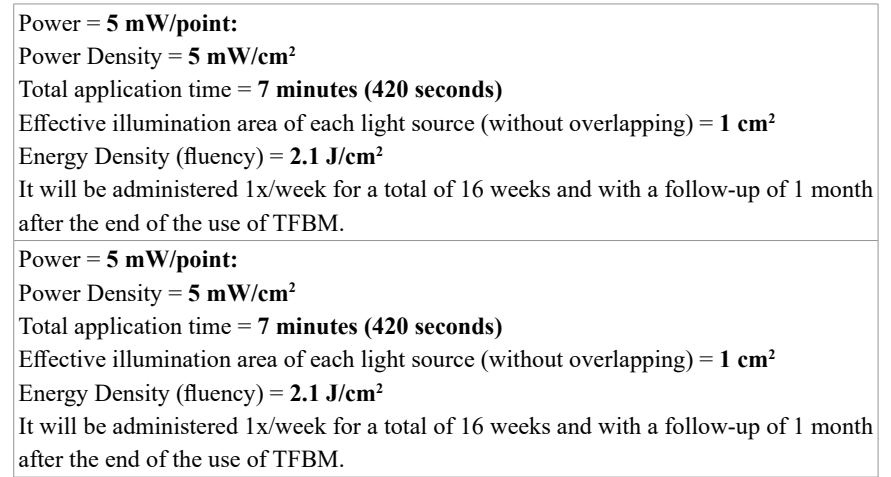

\section{Dosimetry calculation}

Wavelength, in red, $\lambda=660 \mathrm{~nm}$

Diode emits $5 \mathrm{~mW}$ per point $\left(\right.$ per $\left.\mathrm{cm}^{2}\right)=$ as there are 3 points $=15$ $\mathrm{mW}$ per application in total

Area $=1 \mathrm{~cm}^{2}=$ total $3 \mathrm{~cm}^{2}$ ( 3 points of light emission, no overlap among them)

Total power $=15 \times 420=6300$ Joules

ENERGY DENSITY $($ FLUENCY $)=$ POWER $(\mathrm{mW}) \times$ TIME $(\mathrm{sec}$. $\operatorname{AREA}\left(\mathrm{cm}^{2}\right)$ $\mathrm{cm}^{2}$

Energy density $($ creep $)=15 \times 420 / 3=6300 / 3=2,100 \mathrm{~J} / \mathrm{cm}^{2}=2.1 \mathrm{~J} /$

POWER DENSITY $($ IRRADIANCE $)=$ POWER $/$ AREA $=15 / 3=5$ $\mathrm{mW} / \mathrm{cm}^{2}$

\section{Inclusion criteria of patients in the study}

Inclusion criteria are:

- Patients of both sexes.

- Adults between 35 and 70 years old. 
- Asymptomatic or not.

- Patients with GRADE I, II or III NAFLD diagnosed by abdominal ultrasound.

- Overweight or obese (body mass index equal to or greater than 26 $\mathrm{kg} / \mathrm{m} 2)$.

- Other comorbidities not present, since the medications used to treat these diseases would affect the study by interfering with the liver regeneration process, and in addition, an AST/ALT ration $<1$.

\section{Exclusion criteria}

Exclusion criteria are:

- Patients with advanced liver disease, thyropathies, neoplasms, type I and II diabetes mellitus.

- Patients with liver, cardiothoracic and renal failure.

- Individuals with collagenosis and autoimmune diseases.

- A history of alcoholism (ethanol use $>20$ g/day by women and $>40$ g/day by men).

- Patients with hepatitis B or C, or HIV.

- Patients using medications known to cause and treat steatosis or who have recently used the medication metadoxine.

- AST/ALT ratio $>1$.

- Patients who do not follow the recommendations of diet and exercise.

- Specific contraindications to treatment with magnetotherapy [23]:

- suspicion or confirmation of neoplastic processes,

$\circ$ hyperfunctionality of the thyroid and adrenal glands,

○ severe myastenia,

○ Bleeding,

○ bacterial, fungal and viral infections.

\section{Magnetotherapy precautions}

According to Quintero [24], some special precautions should be taken in the use of CEMP, such as the use of pacemakers by patients since the magnetic field could alter the adjustment of the electrical rhythm of this device when administered in proximity to the cardiac regions. CEMP should be avoided in patients during pregnancy, and among those with epilepsy, severe arteriosclerosis, or hypotension, and anticoagulated, hypotonic, or psychopathic patients.

\section{References}

1. Papandreou D, Rousso I, Mavromichalis I (2007) Update on non-alcooholic fatty liver disease in children. Clin Nutr 26: 409-415. [Crossref]

2. Chitturi S, Farrell GC, Hashimoto E, Saibara T, George KKL, et al. (2007) Nonalcoholic fatty liver disease in the Asia-Pacific region: Definition and overview of proposed guidelines. J Gastroenterol Hepatol 22: 778-787. [Crossref]
3. Eifler RV (2013) The role of ultrasonography in the measurement of subcutaneous and visceral fat and its correlation with hepatic steatosis. Radiol 46: 273-278.

4. Nalbantoglu I, Brunt EM (2014) Role of liver biopsy in nonalcoholic fatty liver disease. World J Gastroenterol 20: 9026-9037. [Crossref]

5. Ong JP, Younossi ZM (2007) Epodemiology and natural history of NAFLD and NASH Clin Liver Dis 11:1-16. [Crossref]

6. Neuschwander-Tetri BA, Caldwell SH (2003) Nonalcoholic steatohepatitis: Summary of an AASLD single topic conference. Hepatology 37:1202-1219. [Crossref]

7. Public Health England (2018) Official statistics - liver disease profiles: Short statistical commentary.

8. PARISE ER, Mendonça Son, HTRF (2013) Hepatic steatosis: Hematological and cardiometabolic vision. Ed MTS, São Paulo.

9. Griffen Wo JR, Bivins BA, Bell RM (1983) The decline and fall of the jejunoileal bypass. Surg Gynecol Obstet 157: 301-308. [Crossref]

10. Ludwig J, Viggiano TR, Mcgill DB (1980) Non-alcoholic steatohepatitis: Mayo clinic experiences with a hitherto unnamed disease. Mayo Clin Proc 55: 434-438. [Crossref]

11. Edmilson J, Mccullough AJ (2007) Pathogenesis of non-alcoholic steatohepatitis: Human data. Clin Liver Dis 11: 75-104. [Crossref]

12. Brunt EM (2001) Nonalcoholic steatohepatitis: Definition and pathology. Semin Liver Dis 21:3-16. [Crossref]

13. Chavantes A, Cristina M (2004) Laser in bio-medicine - Principles and practices. Editora Atheneu, 2009, São Paulo, Brazil.

14. Araujo LMG, Chavantes MC (2019) Photobiomodulation therapy in nonalcoholic hepatic fatty disease. Doctoral thesis.

15. Chavantes MC, Holanda VM, Pinto NC, Belotto RA, Zamuner SR, et al. (2017) Applications of laser therapies in medicine. In: Fernandes, Ferrari, France (eds). Biophotonics: concepts and applications. 13: 222-242.

16. Chavantes MC, Morais T, Pinto NC, Tomimura S, Assunção B, et al. (2014) Study's significance from arterial elasticity and variation in arterial blood pressure for normotensive and hypertensive patients applying pre and post lasertherapy: Preliminary results. BIOS-Proceedings 46: 8926-8977.

17. Kazemi khoo N, Iravani AM, Arjmand M, Vahabi F, Lajevardi M, et al. (2013) A metabolomic study on the effect of intravascular Laser blood irradiation on type 2 diabetic patients. Lasers Med Sci 28:1527-1532. [Crossref]

18. Fukada E, Yasuda I (1957) On the piezoelectric effect of bone. J Physiol Soc Japan 12:1158-1162.

19. Martínez Escudero C, Capellas Sans L, Tinoco Gonzáles J (2001) Magnetotherapy in consolidation delays. Rehabilitation 35: 312-314.

20. McLeod KJ, Rubin CT (1992) The effect of low-frequency electrical fields on osteogenesis. J Bone Joint Surg Am 74A: 920-929. [Crossref]

21. McCarthy CJ, Callaghan MJ, Oldham JA (2006) Pulsed electromagnetic energy treatment offers no clinical benefit in reducing the pain of knee osteoarthritis: A systematic review. BMC Musculoskelet Disord 7: 51. [Crossref]

22. Nindl G, Johnson MT, Balcavage WX (2004) Low frequency electromagnetic field effects on lymphocytes: potential, for treatment of inflammatory diseases. In; Ayrapetyan SN, Markov MS (eds) Bioelectromagnetic Medicine. Marcel Dekker, New York, 368-389.

23. Silva RMV, Costa LS, Meyer PF (2010) Effects of magnetotherapy on muscle tissue healing (Course Completion Paper) - Potiguar University of Natal, Natal.

24. Quintero HC, Hernandez DR, Madan GH, Lio LN, Ramírez MD (2002) Physical agents in the treatment of chronic obstructive pulmonary disease. Rev Cubana M ed Milit $31: 119-125$.

Copyright: (C2021 Miachon MD. This is an open-access article distributed under the terms of the Creative Commons Attribution License, which permits unrestricted use, distribution, and reproduction in any medium, provided the original author and source are credited. 